Stanistaw Olejnik

\title{
A Perspective of Moral Theology on the Problem of Tissue Donation and Organ Transplantation*
}

\author{
The Problem
}

The development of medicine in the quarter-century after WWII and especially the medicine of the last few years has found its culmination in successful attempts at transplanting kidneys and the heart; this has become the subject of vivid and hot disputes. Organ transplantation, which has become the basis for the emergence of a new established medical specialty called transplantology, has become the subject of the considerations, discussions and polemics of numerous scholars, the subject of many symposia, conventions, medical congresses, and not only medical ones. The discussion has gone far beyond medical circles. It has deeply affected public opinion throughout the world, found a wide response in the mass media, and become the subject of fascination of various scholars; it has also inspired many professional publications and journalist pieces. The discussion, however, has not been dominated by scientific-technical issues but by clearly moral ones. Questions are constantly raised as to whether and if human organs should be transplanted, how should we assess transplantations already carried out from a moral evaluative position, and what position should be taken in relation to further actions of medicine in this field. These questions are still valid and continue to be formulated, and attempts are made to answer them from different positions and axiological perspectives.

Moral theology has so far distanced itself away from discussions on the subject indicated herein. Unfortunately the opinions of Catholic moralists are missing part of it. This may come as a surprise because it is a matter of a clearly ethical nature, although, it is so deeply disturbing for a wide range of intellectuals. Those who have so recently been accused of too frequent and too punctilious 
interference in human life valued with the use of a ready-made system of assessments and norms, now appear to be holding back from taking a position on the case. Admittedly one can indicate a mere few serious attempts to investigate this subject in the theological literature. One could ask why this is happening. What is the reason for this surprising restraint, or even shyness of Catholic moral theologians, with regard to the consideration of such a contemporary, vivid and disturbing problem?

It seems that the post-Conciliar movement, increasingly more clearly popular in moral theology, focuses the attention of its adepts on basic assumptions, somehow the starting points of this theological discipline. The concept itself, its functions and important tasks are subject to thorough analysis and severe criticism. This is what makes some moral theologians give up, at the same time temporarily, from the ambition of such a close interfering with life which is expressed by the moral evaluation of a particular phenomenon. Life itself, however, does not absolve us from this obligation. However, abandoning the function of evaluating human life in a normative manner by means of specific types and ways of acting negates the essential value of this theological discipline, undermines the very sense of its practicing. Recognition of the need to consider the problem of transplantation, in view of the absence of serious theological research studies in this area, prompted me to put forward the above-mentioned problem. It is to be considered from a theological position, so it will be necessary to refer to the sources that are appropriate for it. The aim of these analyses will be to consider, as thoroughly as possible, whether it is possible to reconcile the transplantation of human bodily organs with the Christian understanding of man, his existence and important earthly tasks, as well as vocations concerning eternal life. What underlies the Christian vision of man and his life is the message of the Revelation but it is also shaped by human thought explaining this message in the light of modern knowledge about man. Assuming such an anthropological vision, enriched with the moral source of the Revelation, the phenomenon of organ transplantation should be addressed.

As the subject of assessment one supposes to assume a fact which belongs to the field of medical practice. For people who think superficially such an assessment seems simple because the surface of the fact itself is regarded as simple by them. In fact, this is different. The matter is not simple at all ${ }^{1}$ since it implies several different aspects. It is not surprising then that these various

1 Cf. J. Ziegler, Moraltheologische Überlegungen zur Organtransplantation, TThZ 77 (1968), 153. 
aspects of the assessment will have to be distinguished one by one in succession. First and foremost, however, there is a need to define the nature of the phenomenon under evaluation and to clarify what in fact constitutes the essence of the procedure of transplanting human organs. The clarification will present how the transplantation phenomenon has been evolving over time and the character of the objections it provoked. These will also be the first points of the present considerations. Later, in the article, we will consider successively, starting from the most important ones, moral problems that are associated with organ transplantation. They determine the more detailed aspects constituting the issue whose final and comprehensive solution can therefore be achieved only in the conclusions gathered at the end of the discussion.

\section{Growing Phenomenon}

Surgical transplantations of the living tissue of one human being to another do not yet have a long tradition ${ }^{2}$. It was preceded by successful blood transfusions from one patient to another, as well as surgical operations of the transplantation of tissues and organs performed on animals.

Blood transfusion, performed widely today, has a history of several dozen years. The first attempts, undertaken as if at random, were not carried out without human casualties. However, the basic discovery of Wiener, significantly extended by Hirschfeld, regarding blood groups and the role of the so-called antigen allowed for the removal of the essential risks associated with transfusion. This has initiated what has become massive use today and is a blessing for tens, perhaps hundreds of thousands of patients, who have been saved thanks to the transfusions. The surgical transmission of living human tissue was preceded by transplantation performed on animal organs. It was initiated 50 years ago by French scientist A. Carrel, Nobel laureate, already known in the world thanks to his experiments of breeding outside the body of live tissue taken from the animal body. Carrel conducted heart transplant surgery. He performed a heart transplantation, at the Rockefeller Institute, of a heart implanted in the neck of a dog enlivened with blood by joining the donor's dog blood vessels to the veins and carotid artery of the recipient dog. The successful procedure revealed the technical possibilities of surgical transplantations of living organs. Balley

\footnotetext{
2 Regarding the history of transplantation, cf. W. Ruff, Die Transplantation von Organen,
} StZ 191(1968), 155. 
and Shumway's research developed these achievements to a great extent. The first one succeeded in transplanting the entire heart-lung system taken from one dog in the place of the previously removed system of the donor dog in 1953. The second, in 1960, a successful operation saw the replacement of the heart in the living body of a recipient dog. These operations, in terms of their technical aspect, could have been applied to the human body without major changes. It became even more realistic because simpler transplantations had also been carried out on humans.

Surgical transplantation on humans were initiated with transplantations of skin patches, tendon or bone parts, transferred from one place to another place of the same patient's body. It was about corrective, in a sense cosmetic, treatments carried out on mutilated or deformed, exposed parts of the human body, especially facial or congenital ailments or induced during war or as a result of unfortunate accidents. However, they did not raise any serious objections or opposition. On the contrary, the plastic surgeons removing or mitigating deformities have done great and undeniable favors to their patients. They contributed to improving their well-being, cured their psychological injuries, sometimes helped them to restore their desire to live. A witness of these efforts and achievements in science and surgical art was Pope Pius XII who held a specific position in this matter as a proponent of Christian morality ${ }^{3}$. He did not express any fundamental objections to these kinds of treatments, on the contrary, he emphasized their positive aspects. The only doubts raised by him referred to possible abuses with regard to conducting scientific and medical experiments on people ${ }^{4}$.

The transplantation of tissues from the body of one individual, animal or human, to the body of another one was undertaken almost in parallel with the above-described treatments. An important moment in this process were successful attempts to transplant the cornea of the eye. This type of transplantation had not been condemned or even more seriously challenged by the wider public. Extremely sensitive to emerging phenomena concerning human life and current moral problems, Pope Pius XII took a position on transplantations in an allocution addressed to members of the Italian Association of the Cornea Donors on May 14, 1956. The Pope considered the transplantation of the cornea in the two above-mentioned cases to be morally blameless. He explains his position and justifies it in a similar way with regard to both forms of transplantation.

3 Cf. the speech of Pope Pius XII of 4 X 1958 to the participants of the $10^{\text {th }}$ Congress of the Italian Plastic Surgery Association. AAS 50 (1958), 952-961.

4 Cf. AAS 48 (1956), 459-467. 
The point is that taking the cornea from a donor in both cases is not an instance of a violation of any rights, so it is not harmful to anyone. For the animal from which the cornea is taken is not the subject of any law at all, while human corpses are no longer subject to the law because they cannot be considered a human person.

When proclaiming the acceptability of corneal transplantation, Pius XII indicates in his allocution the wider issue of transplantation bearing in mind the treatments and surgeries known at this time. The moral problem outlined by the Pope consisted in the fact that transplantation did not cause injury, neither was it harmful to the donor of the transplanted tissue nor to its recipient. With regard to the discussion on the moral situation of the recipient, Pius XII warns against introducing elements retrieved from bodies which belong to the different species, into the human body. Namely, it is about attempts to transplant sex organs from an animal, which the Pope rejects as morally despicable and unacceptable.

The development of transplant surgery, however, had been constantly moving forward, supported by the achievements of all medicine and modern technology. This led to the first successful attempts to transplant entire organs, the first ones being kidney transplantation.

In situations where the function of both kidneys stops and a patient is near to death, the solution is to find a willing donor ready to offer one of his two healthy kidneys. Successful transplantation encouraged more doctors to continue the procedure. There were increasingly more patients at risk of death due to a lack of a healthy kidney as well as willing donors, centers and surgeons ready to carry out a transplantation. Several thousand such operations had already been undertaken in the world, the vast majority successfully with patients enjoying life even for a few years after transplantation.

However, the evaluation of these transplantations was not so unequivocally positive and approving, as opposed to the evaluation of previous types of transplantation. Kidney transplants started to be condemned and censored, doubts and reservations were raised about it, both by public opinion, as well as by medical specialists and thinking humanists. There were voices of criticism heard here and there that questioned the moral right of surgeons to undertake this kind of medical interference. The voices of the sceptics and defeatists were superseded, however, by the reactions of wide approval and even genuine appreciation for the unquestionable achievements of transplant surgery.

On the wave of successes achieved in the field of kidney transplantation, attempts to transplant other organs: lungs, liver and the pancreas have unfortunately not gained such widespread acceptance and fame. Moreover, 
their results, despite the hopes placed in them, and even the first enthusiastic evaluations of the press and publicists, turned out to be unsuccessful and have remained as such to this day.

Finally, on 3 December 1967, a fact occurred that engendered the sense of excitement across the whole globe: Dr. Ch. Barnard managed to transplant a man's heart from another human being in Groote Schuur Hospital, Cape Town. The receiver of the implanted heart was Louis Washkansky and the donor was an 18-year-old girl, Denise Darvall, who died as a result of a car accident. Extremely bold, difficult, risky, extremely exhausting for a few dozen health care workers, the operation was successfully completed, a great success of modern medicine. It moved the public, ignited the emotions of people and even divided public opinion. Many people have recognized it as a fact worthy of respect and admiration. It raised hopes and optimism of many potential recipients of a healthy heart. However there were also quite different opinions. ${ }^{5}$ Immediate criticism began to be raised, sceptical voices calling for prudence and warnings, even total disapproval. There were also protests and demands for a strict ban on this type of surgery, demands to cease carrying out transplantations considered to be harmful. A team of surgeons from Jacksonville under the direction of Dr. Hardy had already in 1963 carried out two heart transplantations: one taken from human corpses, the other from a living chimpanzee.

Despite the unfavourable effect, they paved the way for the success achieved in the case of Washkansky because they showed cardiac surgeons the technical possibilities of this type of transplantation. The successful surgery carried out on Washkansky confirmed and popularized this belief. The success achieved by the team of Dr. Barnard was not challenged even by the death of Washkansky, which occurred after living for 15 days with a transplanted heart. After Washkansky, came Philip Blaiberg, who after having received the heart of 23-year-old Clive Haupt, who died of a brain haemorrhage, survived even longer. Though heart transplantations began to become increasingly more popular, many turned out to be unsuccessful and doctors were unable to keep alive many patients with a transplanted heart. However, many recipients of healthy hearts felt as if they were revived, reborn to a new life for a longer or shorter period of time. The successes and failures of heart transplantation aroused anew not only a great interest in public opinion, but also emotional reactions, provoking disputes.

5 Cf. for example J. Wejroch, Wątpliwości rosną w miarę wyjaśniania, "Więźz" 12(1969)2-3, 104-108. 
Public opinion was not only clearly polarized, but it also fluctuated, changing from enthusiasm to harsh condemnation and vice versa ${ }^{6}$. The direction of this polarization was often determined by the life expectancy of the people who had been subject to heart transplantation. However, this life expectancy was not generally long, sometimes months, exceptionally 2 years. The obstacle to achieving full success was the so-called immune barrier that inevitably led to the rejection of the transplant as a foreign object in the body. ${ }^{7}$ Nevertheless, as a result of successful transplantation, a number of people close to death lived days, months, and even, as in the case of 40-year-old American Donald Lee Kominski from Michigan, over two years. It is not known if Kominski is still alive at the time of writing but on 5 December 1970, he had survived for two years, felt good, had a normal social life, could go for walks, and even did minor DIY work at home.

Proponents and advocates of transplantations in general, and heart transplantations in particular, have a lot to be proud of when they refer to the examples of Blaiberg or Kominski. It is only the beginning of the expected successes of transplantology. They are convinced that the complete overcoming of the immunological barrier with the help of so-called immunosuppressants, anti-lymphocyte serum or other means not known of yet today, is just a matter of time. But this fact unfortunately does not convince opponents of transplantation.

On the contrary, what is today a source of joy for transplantology enthusiasts and what raises their hopes for the future, at the same time reveals a threatening perspective to transplantology antagonists and raises anxiety. At the same time, they argue that the crux of the matter lies not at the level of the technical aspect of performed operations, nor more or less perfect surgical art, nor even the effectiveness of current methods or methods expected in the future, but the holistic, human, humanistic perspective of transplantation endeavours and their achievements. They believe, with full conviction, that there is a different, non-immunological barrier. Namely, their human and Christian conscience is concerned and outraged. Thus they have acute accusations and insistent concerns with regard to transplantology. The variety of reservations and the seriousness of the arguments put forward require, therefore, careful consideration.

Cf. J. Ziegler, art. cit., 170.

Ibid., 161. 


\section{Significance of the Problem}

Some of the reservations, sometimes even formulated as severe disapproval, do not have any serious justifications. They are simply a cry of reluctance, an expression of a negative emotional attitude, a manifestation of verbally inexpressible feeling that something inappropriate is happening. Professor L. Manteuffel, an eminent cardiologist, confesses that the thought of heart transplantation arouses disgust in him ${ }^{8}$. He admits that it is difficult to justify but he regards the method of transplantation as an act of humiliation of human dignity. Intuition makes him regard it as a specialization which is erroneous in its very assumption, at the same time arousing anticipation that the distant effects of transplantation may turn out to be unfavourable.

Reluctance or even disgust with regard to the transplantation of human organs, or even the tissues of the donation itself, is associated - in the case of some of opponents - with autopsies and the utilitarian treatment of some of parts of corpses after autopsies ${ }^{9}$. Reverence in relation to the body of deceased people, a special manifestation of respect towards it, is not easily reconciled with any attempt to dispose of corpses in utilitarian manner. Thus they regard the exploitation of the body of a recently deceased or dying person as a profanation of these deep feelings that should be evoked in every human being, especially believers, by the mystery of human death. Admittedly, they realize that today, in hospitals, corpses are dissected after death and organs are harvested, e.g. for histological examination, but they consider transplanting these organs to human beings as a blameworthy and outrageous procedure of utilization the body after death. In justifying their disapproval, which is essentially emotional in its nature, they refer to suggestive comparisons and analogies. When it comes to treating the human body in a utilitarian manner, they ask what makes us different from cannibals or the "ingenious" rulers of the Nazi extermination camps, who used the mass of bodies of murdered victims in order to make soap out of them, using human skin for lampshades or bindings for photo albums. Even if these analogies are not taken too seriously, the reservations in relation to the treatment of human organs, especially of the heart, as a useful object, and therefore only as a means, even if one assumes that they shall be used in a proper and noble manner, still remain valid. For many people, the body is more than a material thing, and the heart is treated by them with special respect and in a unique way. It has often

8 Cf. Etyczne aspekty transplantacji serca. Sprawozdanie z konferencji nauk., "Etyka" 4 (1969), 40.

9 Ibid., 15.27. 
been suggested that the most important source of reservations and resistance with regard to heart transplantations are clearly expressed or tacitly assumed religious reasons, and in particular those that are represented by Christians.

It is quite understandable if one considers how deep the phenomenon of the idealization of the human heart is embedded in the tradition and rituals of the Catholic Church. It should be noted, however, that the inspiration associated with it, which is the source of the attitude condemning the procedure of the utilization of human organs, is rather broader in its nature and concerns the human body in general. This is at least the case with regard to the Catholic Church, where pietism for human corpses is very lively and deep, and there have been no serious reservations about heart surgery or blood donation. It is known, however, that blood transfusion is still a procedure that is considered absolutely unacceptable by certain Christian communities. So if it is not acceptable to collect and transfuse human blood, is it completely understandable to extend moral reservations and objections to heart transplantations since it is so closely connected to the blood? The most serious accusation against people who carry out heart transplantation is that they contribute to the death of the person who is a donor of the transplanted organ.

Transplantation, in order to be effective, imposes a series of strict requirements, including the fact that the collected heart should be able to continue to survive in the body of the recipient. This heart must be alive, so it is necessary to transplant it at a strictly defined time, otherwise irreversible decomposition processes occur that prevent its revival in another body. The removal of the heart in order to perform its transplantation becomes a definitive factor indicating the end of life, it extinguishes in an inevitable and irreversible way the still smouldering spark of human life (though perhaps invisible to the eye of observers and the instruments of doctors).

One should therefore not delude oneself, heart transplant contributes to death, so it is a lethal activity, it is an act of killing a human being. And as such it is an act that violates the basic right of every person, it is an act of injustice and crime, which can be considered a great, fundamental offense against God, the giver and Master of human life. Human life is sacred and inviolable, and therefore every activity that jeopardizes it, no matter what form, should be condemned and forbidden.

The above-mentioned objection, formulated in such an exaggerated way, is repelled by supporters of transplantation with indignation, while appealing to the best intentions of the people who carry out transplantations. Nobody, they claim, causes death, and no one wants to contribute to it; on the contrary, everything is aimed at healing, maintaining life, keeping the donated organ 
alive in the body of a recipient, who is close to death. However, the opponents do not give way, refining only their arguments, with louder accusations.

Nevertheless the matter must be evaluated objectively, not affected by even best intentions of the graft contractors. As undoubted fact they consider the death of the one from which the heart is taken, and many premises justify that this fact makes those who retrieve a heart from a donor responsible for his death. At best, they might be accused of not making every reasonable effort in order to save a dying life, to keep it alive as long as possible. Doctors retrieving a heart from a donor do not, however, undertake those efforts. The protection of life and health should always be a criterion of their vocation, a source of respect for their profession and the great trust of patients granted to them and their interference in human life. The possible defence of the transplantation procedure which they undertake with the help of the argument that the organ donor will not live anyway, because he or she cannot live for this or that other reason, is not only incapable of convincing anybody but it also undermines the teleology of their profession and vocation.

Medical specialists who are more familiar with this case refer the objection put forward here against those who remove the heart in order to transplant it from the donor to the fact that they do not endeavour to maintain the lives of dying patients and to the uncertainty with regard to determining the moment of definitive death, indicating how well developed so-called cardiopulmonary resuscitation is. The point is that both from the point of view of common opinion, as well as when one takes into account the newer achievements of medicine, the external symptoms of the loss of life are not yet evidence of the actual, definitive death of a human being. Clinical death, indicated by the phenomenon of cessation of the heart-lung function, i.e. respiratory arrest and cardiac arrest, cannot be equated with physiological (biological) death, occurring only some time later. Medicine knows many cases of resuscitation, that is, bringing back to life people who are (seemingly) dead, people who have been diagnosed with respiratory arrest and have lost heart activity.

The use of artificial lung-heart apparatus contributed to their resuscitation and helped restore their lives. A vivid, spectacular example of such a resuscitation was the procedure - carried out several times - of the restoration to life out from clinical death of the great Soviet scientist, Professor Landau, who suffered a car accident.

It is those very possibilities of resuscitation that become the cutting edge of criticism of the opponents of transplantation. Those in whose hands the patient's extinguishing or even already extinguished life is should protect it to the end with the help of, for example, resuscitation procedures, and not deal a final blow by means of harvesting an organ from the body. 
That is why in the case of their failure they must be blamed for murder even if they did not actually aim to kill the victim. It will not be absurd, anyway, to raise the objection with regard to surgeons performing heart transplants, suggesting that they actually want the death of a dying man, they want it, they are preparing for it, and little is needed to directly cause it. The circumstances of these transplants are so particular that the situation of the surgeons who harvest a heart from a donor is characterized not only by the broadly understood fact of them waiting for an opportunity, but also when the time of transplantation is coming, by waiting for the death of the patient, simply waiting for a chance to take someone else's heart.

Professor W. Forsmann, a great scholar, who was awarded the Nobel Prize in 1956 for his outstanding achievements in the field of experimental surgery, in order to show the wickedness of heart transplantation presents a suggestive picture of two operating rooms where a transplant operation is to be performed. In one lies a dying patient who is waiting for a team of excited and impatient doctors equipped with surgical lancets. And it must be remembered that not only are the surgeons waiting for the death of the potential donor of heart, but they are also waiting on the potential recipient and his family. The expected death of the first patient for the latter group represents hope and a chance for a new life.

Should one not in these circumstances be afraid of attempts aimed at shortening this time of waiting, attempts to cause or accelerate the moment of death, or at least the premature recognition of death? ${ }^{10}$ Opponents of transplantations express the fear that the threat of waiting for the opportunity of taking someone else's heart may increase with the improvement of the technique of implementing these procedures, by making them less risky, simpler and cheaper. There is a risk that in such a situation the number of people willing to be a recipient of someone else's heart will increase significantly which will mean that every patient who is in hospital and who has a healthy heart could become an object of the expectations of people who are reluctant to protect his health and life.

Needless to say, this will seriously widen the scope for various abuses; the registration of potential heart suppliers and transactions related to them may become a daily occurrence. A significant reason for the strong opposition to transplantology are economic and social conditions. Experts in this matter are concerned about the large and increasing costs of organ transplantation and 
expenses related to the further treatment of recipients, which may have undesirable general social consequences. In order to become aware of the importance of this problem, it is worth referring to certain calculations made by competent experts. Professor K. Gibiński emphasizes the importance of calculations carried out in France. 35 billion francs would have to be spent on all those who need a kidney transplant in that country along with a 10-year treatment program associated with it. ${ }^{11}$ The costs in Great Britain are comparable, as a result of calculations made by Professor De Wardener in London where it was established that they would have been around 3,500,000 to $16,000,000$ pounds a year over the next 10 years, not to mention the necessary investments ${ }^{12}$.

These are huge sums, and they are supposed to cover the treatment associated with only one type of transplantation, namely kidney transplantation. It is not without fear that economists, authorities, and even professional doctors struggling with social medical problems are eager to take a look at this problem. Expenses for medical treatment and medical care are subject to specific limitations when it comes to the budget of all countries. Therefore, making transplantology a priority and providing it with necessary financial and human resources, etc. could become a serious threat to the functioning and development of other branches of medicine, for medical care, disease prevention and even, in a broader sense, social welfare. Transplantation, as rightly claimed by its opponents, requires huge financial expenditures which must be continued in long-term post-operative treatment. One cannot transplant someone's kidney without providing him with long-lasting and expensive care.

Due to the fact that we cannot afford it, we should stop this costly, luxurious journey that is leading us to catastrophe. When one has to choose between the treatment of a relatively small number of patients waiting for a transplant and treatment, and even the protection of life in general and the health of large masses of society, choosing the latter cannot pose a serious difficulty from the point of view of thinking people. There is a very thin boundary between such a decision and a complete condemnation of transplantology. However the calculation of the costs required by organ transplantology is not just an economic problem. The necessity to choose one option over another makes it possible to classify this problem into a category of problems that are of a thoroughly moral or socio-moral nature. It is in the name of moral reasons that opponents of transplantations actually protest against the financial expenditures allocated

11 Ibid., 37.

12 Cf. Etyka i problemy transplantacji. Sprawozdanie z sympozjum w Londynie w dn. 9-11 III 1969, "Etyka” 4 (1969), 167. 
to these procedures. The problem of choice seems here to be a macro-ethical issue. It may, however, have its own micro-ethical aspect when in terms of the limitation of the possibilities, and hence the number of transplants, doctors themselves are responsible for favouring a particular type of treatment and to choose one option over the other.

Financial, technical and other constraints must put people responsible for decisions in the field of transplantation in a situation of choice. Here the moral problem of prioritizing becomes extremely difficult and disturbing. If only one heart can be transplanted - for various reasons, e.g. when there are no more technical possibilities, or simply no more donors - and there are many potential recipients who are close to death and who are waiting for the only chance of staying alive, there is a necessity to choose. Any such choice seems unfounded, unjust, ethically unacceptable. Therefore, one should not, at all, put doctors in such a situation. This can only be achieved by removing organ transplantations from the list of possible and acceptable interventions carried out by them. The abovementioned objections against organ transplantations that have been indicated by specialists and wider circles of thinking people can be considered as objections regarding the type of medical intervention directly discussed. However, there are also reservations that emphasize the side-effects of these interventions and those that relate to transplantology only indirectly which appeared somehow on the margins of its hitherto successes and failures.

However there is no need to consider them here in more detail. The transplantation of organs, especially the heart, implies, according to these accusations, a wide possibility of abuse, among which only some have been indicated above. They are most visible in the field of medical and extra-medical experiments, concerning man, his life and death, his personality, feeling and thinking. Modern science and technology have put in the hands of people, including doctors, huge resources and possibilities, almost divine creative power which can be (and sometimes is in fact) a source of abuse, becoming a power capable of destroying and harming people. It appears that people are not mature enough to use this power in a morally decent way, and admittedly this power is constantly developing.

Today medical knowledge and the medical art also have such dangerous power at its disposal but unfortunately many of its adepts are not mature enough to use it in a reasonable way. It is therefore necessary to stop the process of increasing their power and the especially dangerous power over human life and death and the power to exchange parts of the human body. In terms of the continuation of surgical transplantation surgery and improvement of its methods, thinking observers of today's situation who are aware of the anticipated 
progress of transplantology are, not without reason, afraid of attempts to transplant the brain undertaken by contemporary medicine. All the horror and gruesome nature of these actions concern the most sensitive point of human personality; namely it is exposed to the danger of complications and changes, revealing a disturbing perspective of transforming consciousness and losing one's own consciousness in order to replace it by the other's. ${ }^{13}$ The problem of certain personality changes has existed from the very beginning of the history of transplantation. It has become especially visible in connection with heart transplantation. However, it is regarded as not too threatening in the field of the latter type of transplantation, as everyone admits. ${ }^{14}$ In the case of possible brain transplantation, it becomes a worrying and threatening perspective. Concerns related to medical experimentation on humans go much further, although their relation to the progress achieved in the field of surgical transplantation is much looser. Concerns arise especially in the perspective of carrying out artificial (i.e. outside the human body) organ cultures, especially the brain and human foetus.

This perspective, even presented with restraint, without exaggeration typical of science fiction, in all its horror, has a fundamental impact, even if not entirely explicit, on shaping the opinions of opponents of transplantations, although it is connected with them only in a loose manner. The whole collection of objections addressed to surgical organ transplantations has been outlined here. A certain reconstruction was carried out, while difficulties and oppositions, previously scattered in fragments have been collected together and deliberately granted the most far-reaching form of objections. In this way, an arsenal of possible weapons that could be used against transplantation was created.

It is not difficult to notice, however, that it is a weapon of various calibre. The elements collected here that create a negative picture of the discussed phenomenon reveal a great variety, they have a different meaning.

The weight of the charges raised is very different. Some of them seem to be exaggerated at first glance, others seem to be of little importance. In order to assess them justly, it is necessary to go even deeper and, above all, to get out of the closed circle of negative factors. In the process of deepening the perspective, it is worth taking into account, at least at the starting point, the difficulties and reservations with regard to the problem of transplantation which are addressed by public opinion. However, it is necessary to select specific and relevant elements to subject them to a more comprehensive criticism (not limited only

13 Cf. Etyczne..., op. cit., 14.

14 Ibid., 32. 
to calumnies). It seems that it would not be justified, in terms of methodology, to begin with possible abuses that appear almost everywhere. They should be taken into account to some degree but only subsequently, and the more serious of them (by nature more distant) should be postponed at the end of further argumentations. Important issues, i.e. those that relate to specific and key ethical concerns in the field of organ transplantation - as it is easy to discern in the above discussion concerning the objections - are not numerous. The response to these accusations allows us to formulate a critical, in-depth, appropriate position in relation to what is crucial in the phenomenon of transplantation. When it has already been achieved, it will be supplemented with remarks regarding the risk of possible abuse and will help us provide an answer to the general question posed at the beginning of these investigations enabling us to make a comprehensive moral assessment of the discussed phenomenon.

\section{Organ Donation}

Difficulties and reservations in relation to the donation of organs for the purpose of transplantation, even if they are not completely irrational, are basically implied by the position of defence of the donor's endangered sake. However, they are usually overcome by indicating the perspective of helping another man in great need, even despite the risk of incurring some damage. However, the positions are not always easy to reconcile due to both a lack of proper data concerning the donor's actual harm, and the lack of clear awareness of what the situation of another person in need is and what the necessity of helping him/ her implies in terms of new possibilities and obligations. From the point of view of the Christian moral doctrine, it is a kind of interpersonal situation, in which the principle of love applies as the basic premise ${ }^{15}$. It includes, in some aspects of this matter, the power and content of the task expressing justice. Guided by love to a fellow human being, complemented with respect to justice, one must seek a solution to the problem. However, the implications of love are broad because they may concern many completely different matters. It should therefore be applied to the group of goods discussed here, having in mind the so-called order of charity (ordo caritatis) expressing the hierarchy of values defined in the Christian vision of human life. 
The nature of the matter simply requires reflection on the evaluation of a certain moral situation, today not at all exceptional, on a specific type of human activity. Namely it requires the application of a certain moral doctrine to a given type of action. This doctrine should therefore be formulated as more specific normative indications. We are not having them at our disposal in a completed form, although we have assumed serious premises which will enable us to define it. One needs to expose it here - of course within the limits determined by the scope of the present considerations. On the other hand, one should be well aware of the actual situation and of this rather new and specific phenomenon.

The view of the situation in the perspective of the application of certain norms and moral judgments turns out to be complex and two separate variants should be distinguished in it. One should qualify in a different way - from the point of view of moral implications - the act of the donor when he or she decides to donate, through transplantation, his/her only organ necessary for him/her to live, compared to the case, in which he/she donates one organ of a pair, such as one of his/her two kidneys. This fundamental difference requires considering both cases separately.

The conscious donation of one's only organ which is necessary in order to stay alive, e.g. heart or one properly functioning kidney, represents a classic case of the decision to commit suicide. In such a form, it must be rejected and condemned from the point of view of Christian morality. ${ }^{16}$ It is not possible, as part of these considerations, to justify the moral principle that is not specific to the given case but to a general and undisputed one. However, if it was assumed, someone could try to undermine its application in a given case referring to the reasons of a potential donor here which are different to those concerning acts considered as typical suicides.

There is indeed something in this picture that prevents us from classifying it as suicide. The motive of sacrifice makes us recognize it as belonging to a higher order of action when compared to the situation of provoking one's own death because of hard experiences or the fearful anticipation of unfavourable facts in the future. Some may even consider it as an act of heroism, greater than Camusian heroism, and Prometheism. However, it is always a case of contributing to one's own death, and in the perspective of the Christian vision of life - an attempt to appropriate the right reserved for God Himself. For some

16 Cf. A. Regan, Man's Administration of his Bodily Life and Members, the Principle of Totality, and Organic Transplants between Living Humans, "Studia Moralia" 5 (1967), 183-186. 
Christians, this may seem difficult, having the features of suicide, heroism that they can find in the salvific passion of Jesus Christ, or what the most faithful and greatest believers, martyrs, sacrificial victims have demonstrated to the world. We had a telling example of this attitude in the unquestionable heroic deed of Father Maksymilian Kolbe in the Auschwitz extermination camp. The analogy here is however apparent. Jesus Christ was not a suicide like his heroic followers were not suicides although they consciously and voluntarily accepted the deaths imposed on them by perpetrators. The situation of Father Kolbe is also incomparable to the situation of a donor offering his healthy heart to another dying man. An alternative to Father Maksymilian's sacrifice in Auschwitz was the murder of a prisoner by the Nazis while in the discussed case the alternative is natural death, the death of a sick man whom no one can help anymore. The readiness of the hero of Auschwitz to accept death was not itself the reason for the crime because this crime was already happening. On the contrary, the readiness with which we are dealing with the case of transplantation, if accepted by surgeons, will make them murderers.

In turn, it remains for us to examine the moral aspect of the problem of the donation of one of a pair of organs. It is no longer the problem of suicide or homicide but it should be considered in terms of serious damage or injury incurred to the human body. Its solution no longer imposes itself in such a unequivocal and evident way, so it is not surprising that it was, and to some extent still remains, a controversial matter, even in the opinion of Christian moral theologians. ${ }^{17}$ As the major premise of this difficulty one can assume the same principle, which makes us utterly disapprove of any suicide attempts, namely, arguing that man is not the master, but only the ruler of this great gift, which he has been granted, the gift of life.

The great tradition of moral thought made us treat partially vital goods, parts and organs of the human body, just like life itself and submit their fate and destiny to the Creator of life Himself. ${ }^{18}$ The minor premise of this difficulty is the obvious contradiction of simple intuition and common conviction with the suggestion that the donation of live human tissue in contemporary transplantations procedures could be considered a simple act of self-harm. It is undoubtedly that the mutilation of oneself in the moral tradition of Catholic thought was

17 Cf. the discussion with A. Regan and J. Kunicic; A. Regan, art. cit., 179-200; J. Kunicic, De organorum transplantatione, "Studia Moralia" 5 (1957), 155-177; A. Regan, The Worth of Human Life, ibid. 6 (1968), 207-249.

18 Cf. W. Ruff, art. cit., 156-158. 
universally assessed as an act of evil and wickedness ${ }^{19}$. One can assume with great probability that such a conviction is held not only by the believers of the Catholic Church and it could be supported by non-trivial arguments. Some Catholic moralists have gone so far as to reject self-injury, claiming that it is an act that is inherently evil and therefore never permissible.

However, they tried to precisely define what should be qualified as such a severely evaluated act of self-injury. Certain cases of harming one's own body were not included in this qualification, just as certain types of not telling the truth went beyond the definition of a lie that was always condemned, or else, to use another example, specific facts of appropriating someone else's belongings were not judged to be immoral because they do not fall within the concept of theft.

There was generally no doubt about the moral evaluation of the surgical treatment. Self-mutilation necessary for one's own body, in order to protect one's life or health was considered fair and acceptable. The theoretical moral justification of this kind of mutilation was quoted in the official teaching of the Church (Casti connubii Encyclical) by Pope Pius XI formulating the so-called the principle of totality (principium totalitatis), to which he referred many a time and whose content was elaborated by his successor Pius XII. The latter, developing the implications of this principle in a speech to the XXVI Congress of the Italian Association of Urologists on 8 October $1953^{20}$, laid down the conditions, formulated criteria for the fairness of amputation of parts of human body and of anatomical and functional mutilation carried out by doctors.

Generally speaking, they consist in determining whether such mutilation is really necessary and whether there is a serious chance of curing the patient as a result of such a treatment. The concept of self-injury qualified negatively did not include in the traditional Catholic moral doctrine other damages performed on one's own body, in the case of a collision of goods and duties. This applies not only to situations occurring during the war. Considering the situation of a man who was innocently imprisoned, chained to a prison wall, the moralists were inclined to grant him the right to cut off his hand if that act would contribute to regaining his freedom.

In recent times, when medicine has already achieved considerable success in the transplantation of human tissues, Pius XII in some of his speeches, e.g. the one addressed to the participants of the Congress of Histopathology on

19 Cf. A. Hamelin, Zasada całości (principe de totalité) i swoboda rozporządzania sobą, "Concilium" (1966-1967)1-10, 203-206.

20 Cf. AAS 45 (1953), 673-679. 
13 November 1952 contributed to the positive moral evaluation of transplantol$\mathrm{ogy}^{21}$. When taking advantage of medical interventions known at the time, one should, as he warns, observe the principle of totality which can be interpreted in an extended way, namely in the sense that body parts are subordinated not only to the body itself, but also to the totality of human individual.

On the other hand, it would not be acceptable to understand this principle in the sense that one can also regard the community, even the supernatural community of the Mystical Body of Christ as this superior totality. Such a rather narrow interpretation of the principle of the totality presented by the Pope with regard to transplantation made some moralists (e.g. Healy) maintain the conviction that donating one's living organs to others is a kind of self-mutilation and should be evaluated negatively. However, most Catholic theologians did not follow their line of reasoning but they opted for the already proposed ${ }^{22}$ (and justified by those interested in osseous tissue transplantation) the thesis that transplantation of tissue from one person to another should not be completely rejected as impious. These theologians have used very different arguments, referring to the sometimes overly broad interpretation of the principle of totality which provoked objections due to both their obvious non-compliance with the criteria defined in the teachings of Pius XII as well as the harmful and dangerous consequences to which too wide interpretation - extended on the level of social goodness - of this principle can lead ${ }^{23}$.

However, the difficulty emphasized here was successfully overcome and it would not be easy to find a Catholic moralist today who would completely reject tissue transplantation, even in the form of organ transplantations, recognizing them as mutilation carried out because of impious reasons.

It was not without reason that the position against the transplantation of organs, of even minor correlative transplantations, let alone blood transfusions has been reduced to absurdity by demonstrating its alleged wickedness. We know, however, that they have not been condemned, not even by the otherwise severe and critical Pope Pius XII, who expressed his legitimization and support for them.

In light of the absurd consequences implied by the position that defends the far-reaching principle of "inviolability" of the right of an individual to have his/her own body at his/her disposal, it is not difficult today to refute the objection addressed to the consent of the organ donor, and which holds that the

Cf. AAS 44 (1952), 786-788. 
donor has no right to decide because only God is the absolute master and the only administrator of the parts and organs of the human body. Without questioning God's right to human life and body, it would be difficult to deny man the right to manage his life and body in a prudent way, guided by love. This justifies not only the possibility of a reasonable initiative in managing the gift of life but also the need to include this good in the hierarchy of values in general, to dispose of all goods that are a God's gift and at the same time the task of every human being ${ }^{24}$.

Bearing in mind the hierarchy of values, one must explicitly recognize that bodily goods are not the most important ones. Therefore, in the defence of other, higher goods, it is necessary to sacrifice not only one's bodily parts and organs but also life. Considering the aspect of intersubjective relations, it would be right to defend the principle that for the salvation of your neighbour you can, even under certain conditions, sacrifice the good of your own body, including life.

However, such a sacrifice of one's own vital goods for the life and health of another person cannot be justified. Therefore, the argument that defends transplantation, asserting that what should be undertaken for oneself should also be done for others, must be considered inadequate and insufficient. This principle is correct when there is no obvious and serious damage being done by an act of helping others. The subject of this damage was thoroughly analysed. It was not without reason that it was considered a key to resolving the problem in terms of moral evaluation. On closer examination, it appears that one can seriously weaken or even question the balance of losses and profits presented here. Even in terms of vital goods, this balance is not completely unambiguous, in the sense of losses suffered by a potential donor. Of course, the opinion of specialist doctors must be decisive in this respect. This position was expressed (considering kidney transplantation) by some prominent foreign surgeons but also Polish specialists in kidney surgery and Professor Orłowski and Professor Nielubowicz confirmed its correctness and expressed their support for it. ${ }^{25}$ They do not deny that the donation of a healthy kidney is a big loss for the body but failure to do so may prove to be an even greater loss. In order to break the immune barrier, doctors transplant only kidneys offered by members of the closest family. Often it is the mother who makes this precious sacrifice for her fatally sick child. If it was not accepted, or if it was not offered, the real threat

24 Cf. J. Ziegler, art. cit., 155-159.

25 Cf. Etyczne..., op. cit., 22.32. 
of the death of the child could arise which in the context of mother's awareness that the child's life was to be saved would become more dramatic and harmful to her health than depriving her of one of her healthy kidneys.

This non-elaborate example reveals the perspective of a different balance other than the one that spontaneously imposes itself and which includes only one aspect - the good of health and life on the side of the donor. A sacrificial gesture of giving up one's own organ cannot be measured in the category of vital goods only (bonum vitae). It is granted its proper dimension in the category of personal goods. Its full justification is achieved at the level of deeper personal values, spiritual values, both in terms of the donor and the recipient. True, deep self-love can, in the act of donation of a healthy organ to another person, find its deep affirmation and enhancement because this gift is not only an expression of love but it enriches the human being and improves him internally at the same time. Certain damage to the welfare of the body is compensated here, perhaps with a great surplus, by a particularly valuable enrichment, in terms of spiritual values. It contributes to a increase in the value of the person to whom the whole body and its parts are subjected ${ }^{26}$.

It would be futile to question whether it is fair to donate an organ for transplantation due to a certain "inviolability" of a person in relation to the requirements of the good of others. The reasons underlying the objection may be justified here, since personalistic reasons must prevent the absolutization of the good of others in relation to legitimate interests of each human person.

However, one should always take into account that the closest relation with other people is implied by the very concept of a person. This relationship also implies some assignment of the vital goods of one person to the same class of goods of others, especially relatives. From the point of view of a thinking person this is clear in terms of a natural community between people. For a Christian, this becomes even more apparent when he takes into account of the dimensions of the supernatural community in which the Christian person stands in close real relationship to others within the totality of the Mystical Body of Christ ${ }^{27}$. The body belongs to a person and should serve it and be subordinated to it.

The human individual is not a predetermined, static reality; he undergoes a process of being, transformation, development, he can achieve new qualities and improve himself. Moreover he is not isolated from others in this process. Only in relation to others can a person fully realize himself, his value and his

26 Cf. A. Regan, Man's..., art. cit., 194-199.

27 Cf. J. Kunicić, art. cit., 170-175; J. Ziegler, art. cit., 163. 
limits. In relations with others he becomes himself. He becomes a complete person when he can give himself to others and sacrifice himself. By offering good to another person, by enriching his subject with a certain "you" he elaborates his sense of personality, enriches himself, develops his own "I". It is not a pure gift, but to some extent debt repayment. The human individual considered in the entire process of his becoming a complete human being has obligations to many other people, also in terms of his vital goods.

When he offers something to others, he repays his debt. This is particularly evident with regard to cooperation in families, in which the donation of an organ occurs most often. However, it does not limit itself to this sphere, yet it finds its legitimization in wide scope of relationships between people. The basic solution of the presented issue, i.e. whether it is decent and morally acceptable to donate your own organ for transplantation has already been achieved in a positive sense.

However, some aspects of the solved problem should be taken into account, some circumstances that can affect the fundamental moral view of the matter. This particularly concerns whether the gift of the organ donation is always justified, does it sometimes take on the form of strict obligations, or if it is the object of a commercial transactions. Organ donation is a matter of great importance and implies paying a huge price on the part of the donor. It can be justified only by giving important reason, i.e. a necessity and real need on the part of the recipient.

One could ask whether, only in the case of the extreme needs of the other human being and thus guided by the intention of saving someone's life, is one allowed to donate an organ necessary for saving the life of another person. Contrary to some of Kunicićs reservations raised here, it is possible to refrain oneself from making such far-reaching demands. It would be decent and noble indeed to donate one of our healthy eyes to someone who cannot see if such transplantation were possible and would guarantee restoring the recipient's ability to see. A considerable difficulty in deciding whether one should donate one's organs, as well when assessing the acceptability of this type of surgery, is the increased danger of loss of life by the donor himself. A problem may however arise, whether it is morally justified, and therefore fair, to expose oneself to the risk of losing one's life, and by donating the organs for transplantation, to save the lives of others. The answer must undoubtedly highlight the legitimacy and importance of removing any unnecessary risk during such a procedure. The existing risk and the possibility of losing one's own life cannot, however, undermine the acceptability of donating the organ. Preventing potential danger is a duty of physicians who, moreover, minimize the risk of death by reducing 
it to a fraction in case of the most serious of organ transplantations, namely kidney transplantation. ${ }^{28}$

Risking human life is not only a frequent, simply everyday phenomenon when it comes to human behavior but can become an act of total sacrifice which is a consequence of love, such love whose admirable perspectives were presented in the teaching and life of Jesus Christ.

The content of the above considerations, in the course of which we assumed that it is necessary to legitimize the moral acceptability of donating an organ for transplantation makes the issue of commitment to this type of sacrifice almost pointless. Organ donation cannot be imposed by anyone. This is, by its very nature, the object of non-binding, yet voluntarily undertaken sacrifice, an act belonging to the category of heroism. We evaluate it like a jump into the water or a fire undertaken in order to save a man exposed to death, however, we cannot oblige anyone to do it. One would even have to, as postulated by doctors interested in this matter, avoid any moral constraint here. This perspective has influenced the aforementioned Polish surgeons performing kidney transplantations making them never, in their medical practice, suggest any of their patients that they could offer their healthy kidneys for transplantation purposes.

They are rightly worried that their proposal could put a potential donor in a situation of constraint. One could only question whether they are making the right decision, always trying to discourage potential donors to donate their organs.

While qualifying the act of donation of one's healthy organ as an act of heroism and demanding that a donor should be granted total freedom of choice when performing it, it is necessary to take into account such, maybe very special and exceptional situations, in which these actions appear as having a clear, though hard to express, feature of moral obligation. It is imposed by love marked by justice, sometimes called pietism, originated in the circle of family and the national community. To understand this problem, it is worth returning to the already mentioned remark that a mother facing the risk of losing the life of her own child and the possibility of saving it through her gift of the donation an organ for transplantation feels a kind of moral obligation to make this gift to her child. However, the situation should be reversed to reveal the proper aspect of the obligation. The mother who gave life to the child is not obliged to give it again. This kind of duty could be however attributed to the child if his

28 Professor Nielubowicz illustrates this problem with a clear example: "It is more or less the same risk that every one of us faces who arrives at work by car every day at $20 \mathrm{~km}$." Etyczne..., op. cit., 31. 
mother were in danger. It would be a special opportunity and a chance to pay off a certain, usually irreparable debt - the gift of life. The child's obligation to pay such a debt exists in equal measure with regard to the father.

Based on a sense of pietism, interpreted in broad context - which would be difficult to explain here - one could still apply this principle to representatives of the good of the nation, its most valuable and most indispensable representatives. Namely that in some specific situations the higher well-being of the fatherland, of the republic, could take the form of a certain internal dictate of conscience, morally forcing its citizen to make a sacrifice of one's own healthy $\operatorname{organ}^{29}$. However, this is an exceptionally delicate matter, requiring additional analyses and considerations, so it would be appropriate to treat the solution given here only as an opinion and hence merely a hypothesis. In order to exhaust the issue of the possible reasons which legitimize our commitments, one should take into account the special vocations to the sacrifice granted to us by God, the so-called the charismatic vocations. They are binding, though purely personal, and completely unattainable to other people and not subject to categories of generalizing assessment.

When one takes into account the special and irreducible dimension and the value of human organs, it would be difficult to regard as fair and decent the actions that would make them an ordinary object of trade agreements. The damage done to the body by organ donation cannot be compensated even by large sums of money. The idea, however, of legalizing trade transactions concerning the donation of organs in accordance with the model of the stock exchange arouses revulsion and 'firm' opposition. This does not mean, however, that no financial aspect should be taken into account when considering the transplantation issue. It returns insistently when one takes into account the costs of transplantation itself and post-operative treatment, in many cases chronic and extremely expensive. It is a matter in all respects justified that the donor does not have to bear these costs. And if precisely because of his sacrifice serious material hardship arose for him, the principle of justice requires that the recipient help him, if possible, to overcome those financial difficulties.

29 A. M. Hamelin tries in a different way, namely by applying the aforementioned principle of totality to the social good to justify the sacrifice of one's own organ for the benefit of others. Cf. art. cit., 206-210. 


\section{Recognition of Death}

With respect to the transplantation of individual organs and those necessary for life, especially the heart, the moral problem is focused on the issue of recognition of death. An unquestionable premise, not only in the circle of Christian life and Christian moral doctrine, is the claim that organ donation should be made only after the recognition of actual death of the donor, never earlier. It is not acceptable to do so with regard to a living person, even if in an agonizing state because it is tantamount to contributing to his death and thus can be undoubtedly regarded as a case of homicide in disguise. Catholic ethics have for centuries put forward a one and unchanging norm that no one has and can never have the right to deprive an innocent person of life; innocent meaning someone who is not that person's current aggressor. It is God's holy and inviolable gift. The mark of invulnerable sanctity carried by the life of every man, also one incurably mentally ill, infirm and old, an unborn child, it is God's gift, sacred and inviolable. Also the life of a dying person carries this special sanctity, so we do not have the right to shorten it, even by applying procedures of euthanasia.

When considering medical activities, it is worth emphasizing that the principle of the inviolability of life here concerns the work and activities of a physician in a special way due to his special calling as a defender of life. Like all people, he never has the right to deprive man of life or shorten a human life. As a doctor, he should protect this life in a positive way, by healing the sick people and preventing the emergence of diseases. Not only Christian revealed ethics but also general human natural ethics included in the teleology of the medical profession, the expression of which can be found in many records of human wisdom, among others in the Hippocratic oath, created by a Greek doctor, the father of European medicine ${ }^{30}$.

Affirmation of the inviolability of human life requires transplant antagonists to question the fairness of removal of vital organs necessary for life, especially the heart. They want to demonstrate with the help of quite suggestive argumentation that there is no question in this case, that is living organs are actually retrieved not from a dead body, but one still alive. When any exaggerated aspect of this argument is removed, it ultimately amounts to highlighting the difficulty in determining the moment of death.

It would not, however, be right to deny the existence of this difficulty or to underestimate it. The participants of the international congress of surgeons, 
cardiologists, biologists and theologians debating for several days from 11 January 1969 in Florence had to confront themselves with this difficulty in all its clarity. The world's most prominent representatives of the scientific disciplines focused mainly on the issue of the boundary between life and death, in relation in particular to the spectacular successes of resuscitation. As emphasized there and elsewhere, the multiplicity and diversity of definitions of death lie at the root of the difficulties. The point is that human death can be understood differently, and therefore the time or the time zone of death can be established in many ways. Therefore, when someone with the help of a specific criterion of life and death regards a moment or condition as a moment of death, someone else, using a different criterion, may reject this way. When a biologist speaks about life, he usually has in mind the life processes of tissues and cells, or simply vegetative life. The cessation of these processes is, from his perspective, a criterion of death.

However, the life of an organism, especially the human body, is something immeasurably more complex, but at the same time much more fragile. The criterion used by biologists indicated above turns out to be completely inadequate in relation to determining its end. Although a man lives a vegetative life, it does not constitute his specificity and uniqueness. Man ceases to be alive when he ceases to live with the whole of his body, even if some tissues still have the ability to live. Cells harvested from cadavers may be cultured as living tissues outside the body, under appropriate conditions. They can live outside the body for a very long time. They are able to outlive, as Prof. K. Rowiński observed, a 120 -year-old $\operatorname{man}^{31}$. However, it would be difficult to regard them as human life as such. When it comes to transplantation, death should be taken into account not in the biological sense but in the anthropological sense. Therefore, it is not a question of determining the death of an organism in the sense of the cessation of all life phenomena in it, and thus the function of tissues and cells, but determining the death of the organism as a whole ${ }^{32}$.

The condition of man, in which it is impossible using the medical means available today to stimulate the symptoms of life in the body as such, is undoubtedly a condition that for the purposes of certain medical actions, such as autopsy, can be considered a state of death. This in turn also opens up the possibility of retrieving and transplanting the needed organ. The life of the whole organism is closely related to the performance of certain organic functions. Some of them are indispensable for maintaining life, and their cessation causes death.

31 Cf. Etyczne..., art. cit., 33.

32 Cf. P. Röttgen, Organtransplantation, WuW 23 (1968), 167. 
Recognition of this detention of organic activities can therefore be considered as death. For a long time, the normal functioning, on the one hand, and cessation of proper operation of the basic the cardiopulmonary system in the human body, on the other hand, was assumed in medicine as the criterion of life and death. Thus the cessation of breathing and cessation of a heartbeat, and thus blood circulation, was regarded as the decisive criterion for recognizing clinical death. Recently this criterion has been considered insufficient. Its validity has been undermined by the aforementioned successes of resuscitation.

Just as it seems reasonable to look for constitutional premises for the specificity of human life in the human brain, it is also legitimate to look there for premises to establish the boundary between human life and the death of the human body. The brain is not only the bodily basis of human consciousness and its spiritual activities. It is also decisive for the integration of the body and life as a whole. So when the proper functions of the brain definitively stop, the human body also ceases to be alive, and death occurs.

The death of a human must be related inseparably and ultimately to the death of the human brain. Its decomposition, caused by the interruption of metabolic processes within its structure, is tantamount to the end of its earthly existence, even if some organs are still able to perform their functions, or even in partial form. The above criterion of human death is widely accepted, and not only among representatives of medicine. If there is a discussion on this subject, it concerns sufficient tests confirming brain death. There are possibilities and ways to determine the death of the brain. The rationale of this statement refers to clinical and electrophysiological symptoms, to the existence or atrophy of cerebral circulation. Encephalograph data is an irreplaceable source of information in this regard. It would of course be an illusion, lack of realism or hypocrisy, not to see certain limitations in these methods. Admittedly they contain non-trivial elements of uncertainty. However, it would be a great mistake to underestimate their value. In spite of their imperfection, they are practically considered a sufficient basis for recognizing death. ${ }^{33}$ There are cases of violent and tragic deaths, for example during a railway crash. When the passenger's brain suffers significant injuries, its death clearly indicates the body's death. However, the heart or kidneys do not have to be destroyed. If these organs are removed in proper time, they can be artificially kept alive and possibly transferred to another person. 
Organ removal in such situations is implied by absolute certainty that the "donor" is dead. The matter of vital importance in such situations is only immediate action because transplant organs may undergo irreversible changes that may cause irreversible disintegration. However the kidneys retain their lifespan longer and can be removed even within a few hours after clinical death and be successfully transplanted. The situation is more complicated in the case of the heart because here surgeons only have minutes. Under ordinary conditions, brain death can be established within a few minutes after clinical death. Brain waves decrease, the electroencephalogram shows defined flatlining, and irreversible changes take place within the brain tissue. Then there is no possibility of sustaining the life of the body, even with the use of resuscitation. Other organs, even the heart, undergoing appropriate resuscitation procedures, can be donated for transplantation and remain in operation for a long time. Under normal conditions of death, definitive death is indirectly confirmed by establishing irreversible changes in the brain tissue. Although absolute certainty cannot be expected in this regard, one must admit that we are not able to achieve such certainty in everyday life either.

In situations imposing the necessity to act immediately and requiring us to undertake definite decisions, we look for conditions sufficient to acquire so-called moral certainty. The higher necessity of saving lives requires making certain decisions, even in case of the absence of knowledge of all theoretically possible implications of specific decisions. This is also the case with recognition of death after noticing signs of brain death. ${ }^{34}$ Death or saving the life of another person, who is waiting for a transplantation may depend on a statement confirming death, a judgement based on moral certainty or practical certainty. When settling a case of recognition of death within a reasonable time one should not overestimate the importance of the possibility and alleged necessity to prolong resuscitation procedures. It is unquestionable that you can achieve the long-term functioning of the lungs and heart thanks to resuscitation. However, it is not possible in such a case to determine whether these sustained bodily functions take place in a living body.

Reanimation is considered an emergency measure in medicine, that is there is very limited scope of cases in which there is an obligation to apply them. One cannot oblige the doctor to prolong for an indefinite time resuscitation efforts, despite lack of effects. Pius XII clearly taught that a doctor has the 
moral right to abandon these efforts if they prove to be useless and no one would have the moral right to accuse him of killing the patient in such a situation. ${ }^{35}$ Surely, a calm expectation, and thus a prolongation of whole procedure after finding clinical death, increases the certainty that the latent life of the body will cease. However, such a waiting time may mean that a given organ will not be suitable for transplantation anymore, thus taking away the last chance of saving the life of a sick person waiting for this gift. It is a fact that cannot be omitted by the defenders of an attitude of "waiting" as long as possible for the actual death of the donor that any increase in certainty as to the fact of his death in the same way contributes to reducing the potential effectiveness of transplantation. ${ }^{36}$

Until recently, early recognition of death was of no more importance in a positive sense - to the life or death of another human being. The possibility of organ transplants necessary for life has completely changed this situation. You cannot wait too long because the life or death of another person is at stake. $R$. Kautzky gives a suggestive picture in order to weaken the position of those who in an extreme way understand the obligation to "wait": to prevent the extinction of the smoldering flame of life. ${ }^{37} \mathrm{~A}$ fire truck car drives through the city streets. Its speed may endanger or kill a passer-by. The driver of the car knows this, driving at high speed, and yet, if someone falls under his wheels, the driver cannot be considered a killer. The reference to the above image leaves much to be desired and the analogy is quite loose. Its importance however consists in the fact that it emphasizes the idea that suffering death in order to save someone else's life is not only unintentional but even completely accidental, although in the overall balance it is regarded only as a sad but unavoidable eventuality. Allowing for the possible death of a patient cannot be considered tantamount to murder. On the contrary, it should be considered fair and acceptable when it comes to defense of the great value of human life. In the discussed case, it constitutes only a margin of risk associated with possible sacrifices incurred in the name of a noble and great work of medicine: the defense of human life.

35 Cf. Speech of Pope Pius XII to the Congress of Doctors and Scholars from November 24, 1957 dedicated to the issue of resuscitation, AAS 49 (1957),1027-1033

${ }_{36}$ Professor Orłowski describes how carefully one makes sure in his clinic that the organ to be transplanted is taken from a person who actually died. Death is confirmed by three independent doctors who do not participate in the transplantation. "Only after the confirmation of death is a kidney is removed. The negative aspect of this procedure is the fact that after such a time the kidney is often not suitable for transplantation." Etyczne..., op. cit., 23.

37 Cf. R. Kautzky, art. cit., 318. 


\section{Rationale of Pietism}

It may be assumed that it is possible to transplant the organs necessary for living from the body of the deceased - through transplantation - to another body, and thus without causing anyone's death, however, this procedure is sometimes considered unacceptable due to the lack of respect for human corpses. The reservations formulated above featured a special kind of respect that we address the corpse with, an almost religious respect and that which has its origin, most probably, in religion. According to these reservations one is not permitted any kind of utilitarian treatment of human corpses, in whole or in parts. It is indeed a fact that the human body is addressed by Catholics with special respect. However, respect for corpses is not the property of Christians alone, but is shared by followers of many other religions as well as non-believers. The Christian religion refers to a few reasons justifying this respect, setting a moral postulate to maintain it.

They are related to the value and dignity of the human body in general, based on the mystery of the Incarnation, connected with the Christian hope for the resurrection of the bodies of the dead, in an eschatological perspective in particular. Christian moral doctrine has always prohibited the profanation of corpses; it required that they be buried in a meticulous way, and the cemetery, a place of eternal repose, was treated as sacral, almost on par with temples and with the sanctuaries of divine worship.

The Christian tradition created various rituals demonstrating manifestations of respect for corpses, as well as in various ways understood the problem of their profanation. The Catholic Church throughout its entire bimillennial history maintained the habit of burying dead people and allowed cremation only in exceptional circumstances. Only recently have the regulations regarding church sanctions in relation to those who expressed the will to be cremated and not buried after death been eased. Even in modern times, strict prohibitions on performing autopsies were in force. They resulted only from pietism for the human body, whose disarming after death was regarded as a simple act of desecration. The problem of the utilization of corpses did not exist in the past, there was simply no perspective of using the body. Exceptionally, one could imagine a situation in which lost travelers from broken ships resorted to cannibalism out of starvation. Well, in this situation there was only a clear prohibition of depriving someone of life, while the possible intake of the body of the deceased was not considered controversial, it was not stigmatized as an act of moral offense. The use of certain parts of the body of people dying in the Nazi extermination camps was a vivid example of the issue of the utilization 
of bodies, shocking the general public of the world which reacted violently against the barbarity of such acts.

The use of human corpses in post-mortem examinations for the purpose of training future doctors and for medical research has been practiced for a long time all over the world and does not cause major objections on the part of the public. Only a clear objection of the deceased himself, expressed before his death, or his immediate family if his death does not raise any suspicion, can stop doctors from performing autopsies. The utilization of human corpses in the form of autopsies is nowadays not considered a desecration. Of course, it must be clearly stated that pietism for corpses requires proper behavior, which is respectful, in relation to corpses undergoing the autopsy. Retrieving an organ from a corpse and its storage in a dissecting room for laboratory and training purposes was not stigmatized as an abuse. There are also no serious reasons to question the fairness of transplants because of the suspicion that the corpses are not treated with due respect. The accusation regarding the utilization of organs of the body becomes groundless when one takes into account precisely the servile, utilitarian character of each organ in relation to the living body which would be saved thanks to them. The organ that served the body during life, removed after death and passed on to another body, may continue to fulfill its role. Its character does not change, only the object with regard to which it fulfills its role. The previous entity does not lose anything because it does not need this service. Serving life cannot be considered a disgraceful act. The Christian religion does not raise any serious objections with regard to heart transplantations related to the fact that the transplanted organ is serving a new body. The idea of service and love, so present in Christianity, associated with the heart in general, and the heart of Jesus Christ in particular, seems rather to favor transplants. Sharing with others, the gift of goodness, sharing your heart, serving it to other people are not shameful acts, but on the contrary, they are acts of nobility and goodness. Even when the deceased has refused to give his heart to someone, transplantation should not be considered an unacceptable act. One can easily accept the default consent of the latter. In the case of the explicit opposition of a dying person, his/her will should be respected, and only in exceptional cases, when considered unreasonable and groundless, can this opposition be ignored. The tradition and the position of public opinion are very important in a given case. One has to respect them because in the field of morality tradition is a factor of great importance. 


\section{Practical Difficulties and Possibilities of Abuse}

It is not without reason that opponents of kidney and heart transplants emphasize the great financial costs of these operations as well as those related to the further treatment of recipients. Nevertheless, it must be clearly stated that this economic factor cannot be significant in assessing the fairness or unrighteousness of the transplantation itself. Only the medical professions of economically and technically developed countries can afford such activities. Poor countries are disadvantaged in many areas which is why wealthy nations face the obligation of supporting developing countries.

These poor countries, however, do not have, at least temporarily, a moral problem of the acceptability of human organ transplants. The issue of preferences in the field of state funding of particular branches of medicine is a problem of the economic and social policy, not free from moral aspects. In general, it would be unjustifiable, or even unacceptable, to allocate large amounts of tangible and intangible resources to experimental medicine, and in particular to organ transplantation if this would be a great loss for general medical care or general social care. Indeed, it would be immoral to prioritize saving the lives of a few people by using extremely expensive means of saving life and treatment while depriving many other patients of ordinary help and medical care. Therefore, taking financial possibilities into consideration must highlight the decision to undertake organ transplant operations, especially on a larger scale. The inadequacy of funds is a serious circumstance that can make such operations an immoral act. However, it must be clearly stated that this is not a sufficient reason to reject and condemn organ transplants in general. Considering today's state of medical science and art, human organ transplants are regarded as emergency treatment measures. According to principles adopted for centuries in moral theology, no one is obliged to apply such measures. In the past, all kinds of surgical procedures were considered to be of this kind, even those considered as easy and non-risky today. Until recently, moral theologians released patients from the obligation to make decisions on a surgical operation referring to the otherwise recognized principle that emergency measures do not apply in the case of dilemmas of the conscience. Today the situation has changed radically. Nevertheless, organ transplantation has to be considered as an emergency measure for several reasons. The obligation to use them on a macro or micro scale cannot be taken into account at all. However, this does not mean, of course, that it is necessary to condemn and reject their use in general. Applying them, on the other hand, may be to some limited extent something necessary and recommended due to the further progress of medicine, 
in other words medical knowledge and medical art. Measures and activities that are considered extraordinary nowadays due to the progress of medicine may become ordinary in the future.

It would be unreasonable, therefore, not to take advantage of them, even if only to a very limited extent, as far as human resources and material capabilities are concerned. With limited possibilities of transplantation, the problem of preferences and the selection of priority and secondary procedures is faced by doctors who perform them. This is, as we have seen, a difficult and regrettable issue. Granting one person a chance of life is often tantamount to taking away this chance from others. Thus doctors often have to hesitate when choosing. Even in case of the best result of the operation and saving the life of a person with a transplanted organ, they may sometimes suffer from a feeling of guilt due to somehow condemning others to death. This may explain far-reaching demands not to put a doctor at all in the situation of such a choice. However, it is worth considering several important premises that will allow us to resolve this painful undoubtedly and difficult problem that nevertheless can possibly be solved rationally in a different way. First and foremost, it should be noted that although there may be many who are in need of a healthy heart or kidney, they have no right to receive the organ only because of this need, nor are they obliged to apply for it. Since retrieving the organ from someone else's body is a special, extraordinary, even exceptional measure. The second extremely important moment is that the mere admission of death is never and cannot be equivalent to murder. The doctor is often placed in a situation in which he experiences the limitations of human interference in saving life and must allow the possibility of death as an inexorable necessity. When patients are dying and nobody can do anything about it, the doctor should do everything possible to save them. If it is not possible for the doctor to give those patients a chance to live, he cannot be blamed for their deaths. It would be good if he had in his hands an additional chance to save the life of someone who was "condemned" to death, saved by the gift of a transplant. He can, and he even should take advantage of this opportunity, and it would be unforgivable for him to waste it. A loaf of bread that could save one man from starvation when many die of hunger should not be destroyed because of an alleged injustice that other hungry people will be deprived of it. A loaf of bread could be somehow divided evenly among the many hungry people. It is impossible, however, to endow many patients in need with one heart or a kidney. Therefore, surgeons performing transplants must make a choice. In professional literature and journalism, there has been quite a broad discussion among doctors themselves and among moralists concerning the 
situation of making this kind of choice. Those discussing the issue are aware of the difficulties faced by a physician forced to choose specific patients for whom he is willing to apply an exceptional medical measure. They generally agree that one should endeavor to facilitate the doctor's choice, the decision should be dictated primarily by medical reasons, if they exist. R. Kautzky, admitting the need to take into account extremely different circumstances, believes that the most important premise should be the probability of curing the patient. ${ }^{38} \mathrm{M}$. Sokołowska complements these conclusions stating that apart from professional medical premises one should also include certain (though not precisely defined by her) "indications and contraindications of social nature" ${ }^{39}$. Participants of the symposium held in London on 9-11 March 1966 considering the problem of kidney transplantation, widely discussed the setting of priorities. ${ }^{40}$ Transplant specialists provided the rationale for choosing a patient for transplantation. They admitted that they would rather choose mature, mentally healthy people, those whose treatment gives greater hope for recovery, and finally those who, as fathers or mothers of families, have to raise small children. Also, socially useful people would be more likely to become organ recipients in the first place. The popularity of this principle would be indicated, by a practice, generally approved in the moral consciousness of a society condemned during the last war to extermination, aimed at especially saving intellectuals and writers. The outstanding Polish writer Z. Kossak was reportedly saved from extermination in Auschwitz in this way, on account of a certain 'preference'. It is difficult to determine universally important preferences when it comes to the moral choice of a doctor. Ultimately, the determinants should be their own awareness and sense of responsibility. Their decisions, however, are not able to please many, they may even be wrong for many reasons. As noted by R. Kautzky, quoted above, "sometimes in special circumstances the medical judgment will be debatable, moreover, retrospectively, it may even turn out to be wrong. But ultimately, this is the case with every medical decision, and this circumstance cannot release the doctor from taking responsibility for making that decision." ${ }^{41}$.

If, ultimately, the doctor is credited with the right and the obligation to make decisions, it only increases the respectability of his profession and his vocation but at the same time increases his responsibility. The contemporary

38 Cf. R. Kautzky, art. cit., 314.

39 Cf. Etyczne..., art. cit., 42.

40 Cf. Etyka..., art. cit., 168.

41 Cf. R. Kautzky, art. cit., 315. 
progress of medical science does not reduce, as Professor Gibiński observes, the role of choice which is made by the doctor himself. The scope of his freedom constantly increases and will increase in the future which also results in an increase in the importance of his decisions, and unfortunately also the significance of his eventual error. This statement implies "the need to require from doctors high, highest moral-ethical qualifications" ${ }^{2}$.

Thus, a physician's professionalism, his professional prudence and moral responsibility may be the last word in making decisions regarding the performance of organ transplants and with regard to the selection of patients who are to be endowed with a chance of a prolonged life as a result of this medical method. The doctor should only be careful to avoid making a too hasty choice and selecting specific patients for transplants only because of possible benefits which he might expect for himself. He must be guided by a love of the sick, or mercy supplemented by a certain subtle sense of justice.

To sum up this discussion, we must deal with some difficulties related to the prospect of the further development of transplant surgery, for which organ transplantation already performed can only be a stage for undertaking further-reaching transplantations. This perspective is a matter of concern for many. We have already seen above what they fear most. Experiments on "cultivating" humans in some other organic conditions and personality changes as a result of brain transplant surgery are the most far-reaching possibilities and indeed a nightmarish prospect. There is no reason to disregard concerns about making further possible experiments on the human body carried out by medicine in general, and surgery in particular. Nevertheless, it would be pointless to see only the dark sides of the progress of medicine and judge its future in this respect only in terms of possible abuse and abnormalities in its development. Medicine has made great progress over the last decades and is now serving, with far more elaborated measures and resources than ever before, people in the field of treatment or disease prevention. At the same time, there is hope based on serious assumptions that it will fulfill its task better and better as its capabilities develop. Its dark aspects should be clearly disclosed so that we can prevent them if possible. This would require separate, far-reaching analyses, which is, however, not a subject matter of these considerations. For the purposes of these considerations, it is enough to state that the possibility of abuse of those elements of knowledge and medical art that have been elaborated on by constantly developing transplantation efforts in the 
field of human organs, cannot negatively affect the fundamental assessment of these efforts. Abuse can occur everywhere. Even the best and most sacred can be abused. Taking into consideration potential abuses which may occur cannot paralyze efforts aimed at the progress and improvement of human life. Nor can it, however, make us regard such incidents as moral offenses, if there are no grounds for it. Organ transplants are not the cause - what is the most important thing in morality - but only at most an opportunity for abuse. By nature, they are a chance to prolong life and improve health, which, if it does not contribute to the acceleration of the death of a donor, can be considered morally good. At the same time, they provide an opportunity for medical progress. This is an ambiguous opportunity, since it implies a dark perspective of abuse. However, this cannot and should not affect our opinion on transplantation itself. The risk of organ transplant abuse is of course not limited to the future.

Today there is a risk of abuse in this area, and it is of various kinds. As transplant surgery progresses, the risk can only increase. There is no possibility or need, in the course of these considerations, to analyze more thoroughly the possible abuses related to today's state of transplantology. The most serious cases have been clearly indicated in this work, or have been revealed by the way, in the course of the above-mentioned arguments. It is enough here to warn against them in general, or, along with lawyers and specialist physicians, to call for undertaking all efforts in order to prevent them occurring, e.g. by imposing on practice of transplantation a set of more detailed legal norms. Moralists are more willing to interpret norms in the terms of a code of medical ethics. The danger of abuse in this area of medical practice - as indeed in others - is always real and serious. Doctors are people and experience human lusts and weaknesses. They are often mistaken, and in this way, sometimes irretrievably, tend to cause a lot of harm with regard to their patients. What is worse, they succumb to their passions which blind their ability to make rational judgements and can contribute to causing a lot of harm. In the field of transplant medicine, ordinary human flaws - magnified by their tragic consequences - such as ambition, desire to get publicity, experimental passion, and human antipathies pose a major threat. The postulate to fight with these flaws and not to succumb to them, in order to prevent possible abuses in this area, is the final, general indication of a moral nature presented here. 


\section{Conclusion}

The main objective of the present article was to show what is the crux of the moral problem of transplanting human organs and how it should be resolved from the point of view of Christian morality. The issue posed by contemporary medicine reveals several aspects, therefore it cannot be resolved too hastily. The formulation of the general position on the fairness of transplantation required consideration of several specific issues implied by the general view of the phenomenon under discussion. Considering the situation of the donor, from whom the organ to be transplanted to someone else is taken, leads to the conclusion that retrieving the organ from the body of a deceased person cannot be regarded as impious or immoral.

Similarly donation of one's organ, whose transplantation is not necessary to maintain someone else's life, should also be considered as morally correct. In the case of the donation of an organ necessary for maintaining the life of the donor, one should regard the act as morally condemnable, mainly because of the cooperation of the recipient with doctors, which aims at inflicting death on an innocent person. In certain specific situations, the donation of one healthy organs (from a pair), which is necessary to maintain the life of another person may turn out to be an obligation dictated by family love or the love of the fatherland. The greatest number of reservations and difficulties in the field of organ transplantation concern the issue of the recognition of death, especially in connection with the successes of resuscitation. One should bear in mind the ambiguity of death criteria in the ongoing discussions, from tests of death in a biological sense, through clinical death, ending with the recognition of the death of the brain. Despite the existing discrepancies in opinions, it is possible to declare the death of someone with full responsibility at a time when there is still the possibility of harvesting an organ from that person and transferring it to someone else. A judgement of this type is not and cannot be issued with absolute certainty.

For the goals set in a given situation, it is completely sufficient and can fully justify undertaking transplantation activities. Conscientious consideration of the discussed case allowed the author of present article to conclude that the possible admission of the possibility of death in a given case cannot be identified with the deliberate act of taking someone's life. The final conclusion of this key part of the investigation turned out to favor organ transplantation in the sense that it does not have to involve the accelerating the death of the donor. Practical difficulties with regard to organ transplantation, connected in particular with the need to establish specific preferences as to the selection 
of organ recipients on both a macro and micro ethical scale, are not sufficient arguments which could make us firmly reject their implementation. They can be, however, overcome under certain conditions. They are not, in any case, a decisive argument in favor of rejection of organ transplants in general. Also, possible abuses cannot be regarded as such an argument. It must be admitted that their occurrence is possible, and may pose a serious threat in this regard. Nevertheless, cases of abuse can accompany and indeed they do accompany all human activities, even the most noble in moral terms. In the face of the possibility of abuse, in the discussed area of medical activities, associated with a special kind of risk, it is necessary to appeal to doctors that they should maintain a great sense of responsibility and a noble moral attitude. 